\title{
Effects of different mixed planting patterns on nutrient contents in Cunninghamia lanceolata
}

\author{
Jinbiao Zhang ${ }^{1,2, a}$, Sizu Lin ${ }^{\star 3, b}$ and Bao Liü, c \\ ${ }^{1}$ Analytical Centre, Fujian Agriculture and Forestry University, Fuzhou 350002, China \\ ${ }^{2}$ College of Life Science, Fujian Agriculture and Forestry University, Fuzhou 350002, China \\ ${ }^{3}$ College of Forestry, Fujian Agriculture and Forestry University, Fuzhou 350002, China \\ ajbzhangfj@163.com, bszlin53@126.com, c40511779@qq.com
}

\begin{abstract}
Keywords: Cunninghamia lanceolata; mixed plantation; calcium; magnesium; potassium; phosphorous
\end{abstract}

Abstract. This paper is to study the effects of different mixed planting patterns of Chinese fir (Cunninghamia lanceolata) on nutrient contents in plant. One-year-old seedlings of $C$. lanceolata were used and mixed plantation of $C$. lanceolata with both Michelia macclure $i$ and Schima superba in high planting density was observed. Four main nutrients, including potassium (K), calcium $(\mathrm{Ca})$, magnesium $(\mathrm{Mg})$ and phosphorous $(\mathrm{P})$ in plant, were determined after 18 months. The results showed that K content increased by $17.9 \%$ in root of $C$. lanceolata mixed with $M$. macclurei as compared with pure $C$. lanceolata plantation, while it increased by $48.4 \%$ in root, $22.6 \%$ in leaf of $C$. lanceolata mixed with $S$. superba. Ca content increased by $58.3 \%$ in root and $23.0 \%$ in stem of $C$. lanceolata mixed with $M$. macclurei, while it increased by $9.6 \%-42.8 \%$ in all parts of $C$. lanceolata mixed with $S$. superba. $\mathrm{Mg}$ content decreased in all parts of mixed plantation of C. lanceolata and M. macclurei, with 2.0\%-31.1\% less than that in pure $C$. lanceolata plantation, while $\mathrm{Mg}$ content decreased by $5.1 \%$ in root, $7.9 \%$ in stem and increased by $7.8 \%$ in leaf of mixed plantation of $C$. lanceolata and $S$. superba. P content increased by $17.3 \%$ in root of $C$. lanceolata mixed with $M$. macclurei, while it increased by $0.5 \%-32.6 \%$ in all parts of $C$. lanceolata mixed with $S$. superba. These results indicated that a mixed plantation of $C$. lanceolata with both $M$. macclurei and $S$. superba could improve the nutrient uptake of $\mathrm{K}, \mathrm{Ca}$ and $\mathrm{P}$, but was not good for $\mathrm{Mg}$ accumulation. A mixed plantation of $C$. lanceolata with $S$. superba showed better in above two mixed planting patterns.

\section{Introduction}

Chinese fir (Cunninghamia lanceolata) belongs to subtropical coniferous tree species. It is one of the most important timber tree species in South China and the number and area of $C$. lanceolata plantations is still increasing [1]. With the continuous development of society, the demand for $C$. lanceolata is increasing and becoming more and more important in social economy [2]. However, yield decline in $C$. lanceolata plantations has become a big problem in recently years because of the bad forest management of $C$. lanceolata plantation, such as successive short rotations and slash burning, which caused primarily the depletion of soil nutrient [3-5]. It was documented that mixed plantation was one of useful forest management to overcome above problems because a mixed plantation can drive productivity by influencing all variables in the production ecology equation: resource supply, proportion of resources captured and efficiency of resource use [6]. It has been showed that mixed plantation of $C$. lanceolata with broadleaf forest such as Michelia macclurei could significantly increase $\mathrm{C}$ mineralization in soils [7]. Mixed, sustainable-managed plantations had average $67.5 \%$ more ecosystem $\mathrm{C}$ than traditional pure conifer plantations [8]. Wang et al. [9] also reported that introduction of broad-leaved tree species into pure coniferous plantation improved soil microbial properties and soil fertility, and could be helpful to restore degraded forest soil.

The aim of this paper is to study the effects of different mixed planting patterns of $C$. lanceolata on the accumulation of $\mathrm{K}, \mathrm{Ca}, \mathrm{Mg}$ and $\mathrm{P}$ in plant. One-year-old seedlings of $C$. lanceolata were used and the mixed plantation of $C$. lanceolata with both M. macclurei and Schima superba in high planting density was observed. 


\section{Materials and methods}

\section{Research area}

The experiment was performed in Experimental Station of Forest located at the campus of Fujian Agriculture and Forestry University, Fijian Province, China with geographic coordinates: East Latitude $26^{\circ} 05^{\prime}$ and Northern Longitude $119^{\circ} 14^{\prime}$. The climate is characterized as subtropical mansoon climate.

Soil

The yellow soil collected from the mountain area in Experimental Station of Forest was used for this study. Soil properties were measured before experiment. The results were showed in table 1.

Table 1 Soil properties

\begin{tabular}{|c|c|c|c|c|c|c|c|}
\hline $\mathrm{pH}$ & $\begin{array}{c}\text { Total N } \\
(\%)\end{array}$ & $\begin{array}{c}\text { Total P } \\
(\%)\end{array}$ & $\begin{array}{c}\text { Total K } \\
(\%)\end{array}$ & $\begin{array}{c}\text { Available N } \\
(\mathrm{mg} / \mathrm{kg})\end{array}$ & $\begin{array}{c}\text { Available P } \\
(\mathrm{mg} / \mathrm{kg})\end{array}$ & $\begin{array}{c}\text { Available K } \\
(\mathrm{mg} / \mathrm{kg})\end{array}$ & $\begin{array}{c}\text { Organic } \\
\text { matter }(\%)\end{array}$ \\
\hline 4.29 & 0.048 & 0.017 & 1.48 & 58.9 & 1.45 & 42.3 & 0.7 \\
\hline
\end{tabular}

Mixed plantation

One year old seedlings of C. lanceolata, M. macclurei and S. superba were used as plant materials. Three different mixed planting patterns, including pure $C$. lanceolaota, $C$. lanceolata with $M$. macclurei and $C$. lanceolata with $S$. superba, were compared. Seedlings were planted in high planting density by using soil culture with pot pools (Length $\times$ Width $\times$ Height $=1 \mathrm{~m} \times 1 \mathrm{~m} \times 0.8 \mathrm{~m}$ ). For each planting patterns, there were four replicates. Plant material was sampled after 18 months. Each plant was separated into three parts, including root, stem and leaf. The plant samples were dried at $105^{\circ} \mathrm{C}$ for $5 \mathrm{~min}$, and then at $70{ }^{\circ} \mathrm{C}$ until constant.

\section{Determination of nutrient elements in plant}

0.5-1g dry sample was digested with a mixture of $\mathrm{HNO}_{3}-\mathrm{HClO}_{4}$. Concentration of $\mathrm{K}, \mathrm{Ca}$ and $\mathrm{Mg}$ in digested solution was determined by using an Atomic Absorption Spectrophotometer (TAS-990, Beijing Purkinje General Instrument Co., Ltd). P content was determination by using a UV-Vis Spectrophotometer (DU640 Beckman).

Statistical analysis

Data were analyzed using Microsoft Excel. Values were represented as the means of four replicates (mean $\pm \mathrm{SD}$ ) for each treatment. Differences between different treatments were statistically calculated using Tukey's t-test using SPSS 13.0.

\section{Results and discussion}

\section{Content of $\mathrm{K}$}

The accumulation of $\mathrm{K}$ in leaf of $C$. lanceolata was more than that in root and stem (Fig.1). $\mathrm{K}$ Content increased by $17.9 \%$ in root of $C$. lanceolata mixed with $M$. macclurei as compared with pure

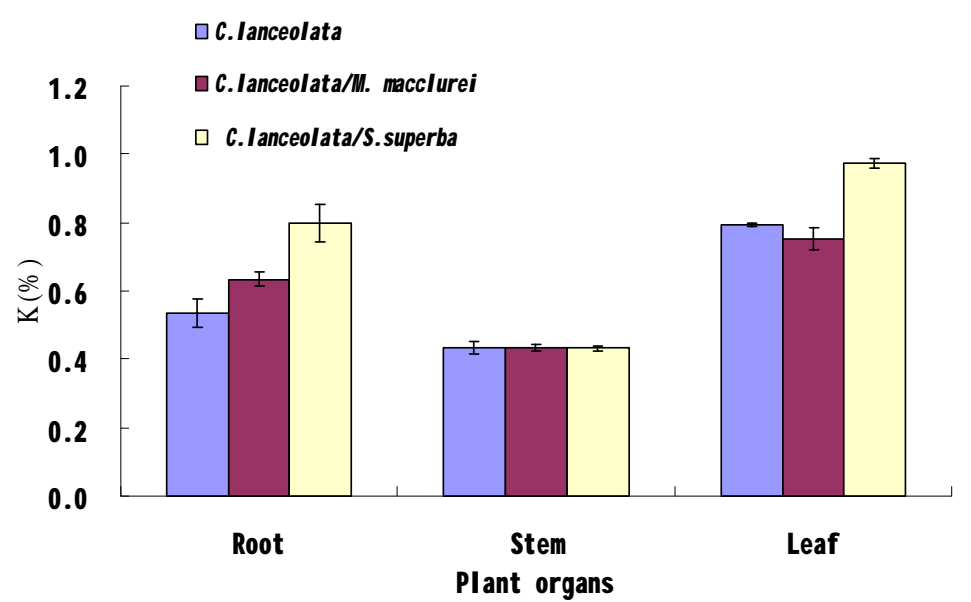

Fig. 1 Effect of mixed planting on $\mathrm{K}$ content in $C$. lanceolata 
C. lanceolata plantation, whereas it decreased slightly in stem and leaf. K content increased in both root and leaf of $C$. lanceolata mixed planting with $S$. superba. The value was $48.4 \%$ and $22.6 \%$, respectively. It is well known that $\mathrm{K}$ was one of macro nutrients in high plant [10]. The results showed that the content of $\mathrm{K}$ increased significantly in some parts of both mixed planting, indicating that the mixed planting of $C$. lanceolata could promote the uptake of $\mathrm{K}$ nutrient.

\section{Content of Ca}

As showed in Fig. 2, Ca content in leaf was much more than that in stem and root. Ca content in $C$. lanceolata increased by $58.3 \%$ in root and $23.0 \%$ in stem of $C$. lanceolata mixed with $M$.macclurei as compared with pure $C$. lanceolata plantation, whereas the content in leaf was decreased by $14 \%$. There was also an increase in Ca content in all parts of $C$. lanceolata mixed planting with $S$. superba. The content in root, stem and leaf was increased by $30.5 \%, 42.8 \%$ and $9.6 \%$, respectively.

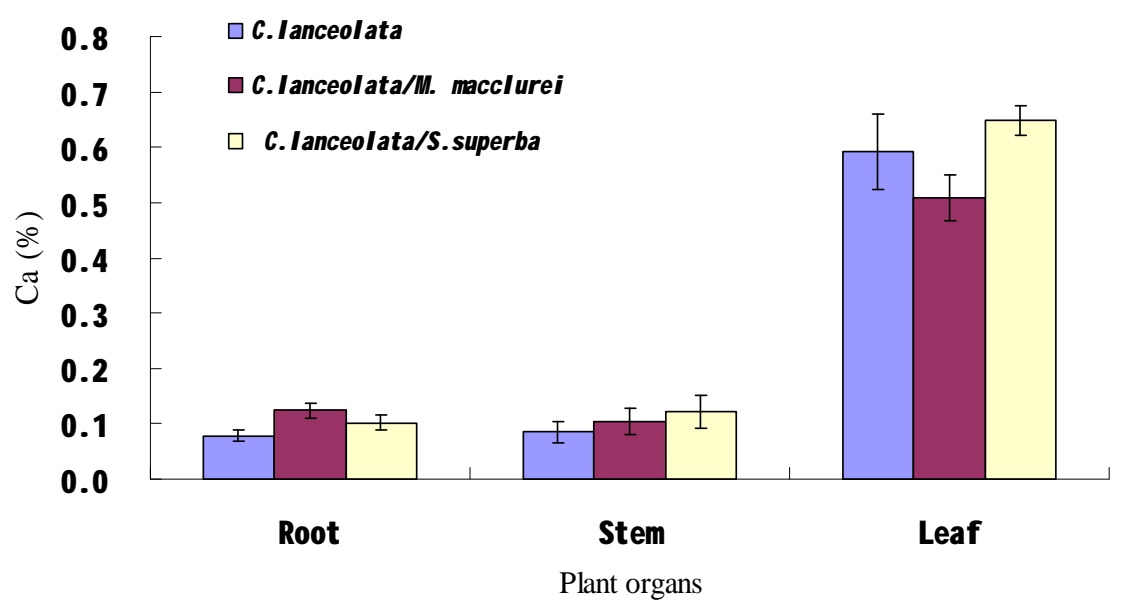

\section{Content of Mg}

Fig. 2 Effect of mixed planting on Ca content in C. lanceolata

As showed in Fig. 3, a mixed plantation of $C$. lanceolata led to a decrease in $\mathrm{Mg}$ content in all parts except in leaf of $C$. lanceolata mixed planting with $S$. superba. Mg content in root, stem and leaf of $C$. lanceolata mixed planting with $M$. macclurei decreased by $29.8 \%, 2.0 \%$ and $31.1 \%$, respectively. $\mathrm{Mg}$ content in root and stem of $C$. lanceolata mixed planting with $S$. superba decreased by $5.1 \%$ and $7.9 \%$, whereas it increased $7.6 \%$ in leaf. These results indicated that a mixed plantation of $C$. lanceolata was not useful for $\mathrm{Mg}$ accumulation in plant.

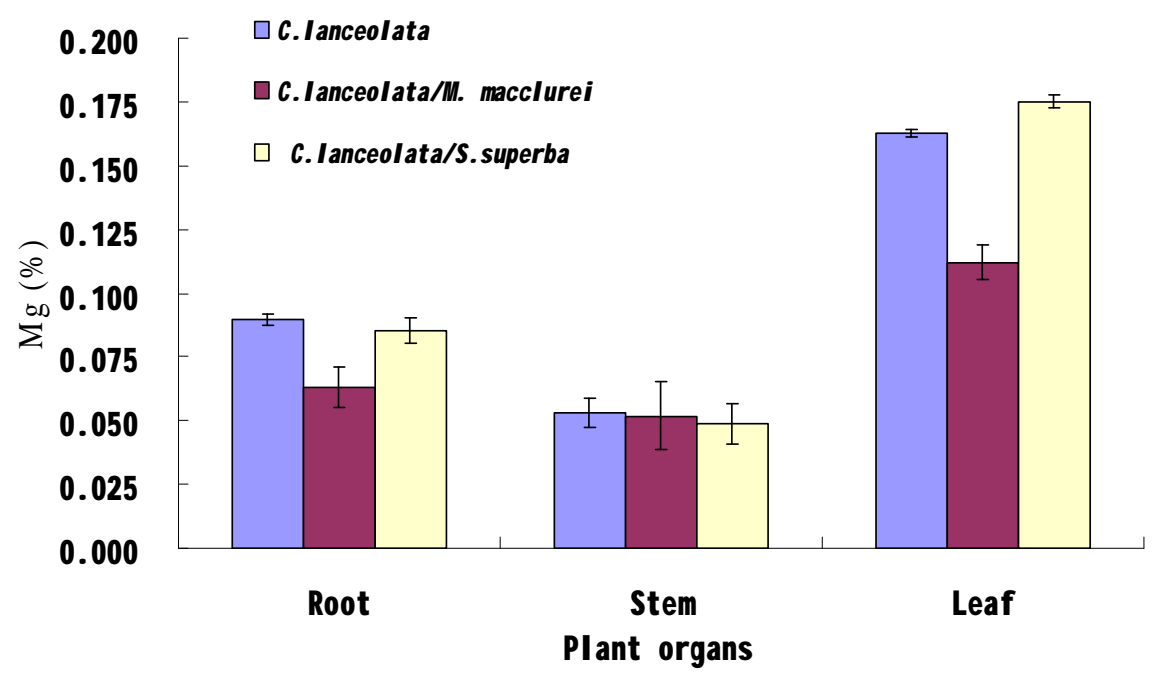

Fig. 3 Effect of mixed planting on Mg content in C. lanceolata 


\section{Content of $\mathbf{P}$}

P content in stem of mixed plantation of $C$. lanceolata and $M$. macclurei increased by $17.3 \%$ as compared with that of pure $C$. lanceolata plantation, whereas it decreased by $19.2 \%$ and $9.1 \%$ in root and leaf (Fig. 4). P content in root, stem and leaf of $C$. lanceolata mixed with $S$. superba increased by $4.3 \%, 32.6 \%$ and $0.5 \%$, respectively. For $C$. lanceolata, deficiency in P availability in forest soils of Southern China is one of big problems, which would greatly affect $C$. lanceolata productivity [11]. Therefore, above results indicated that a mixed plantation of $C$. lanceolata could improve P input, which would be good in the area of P deficient.

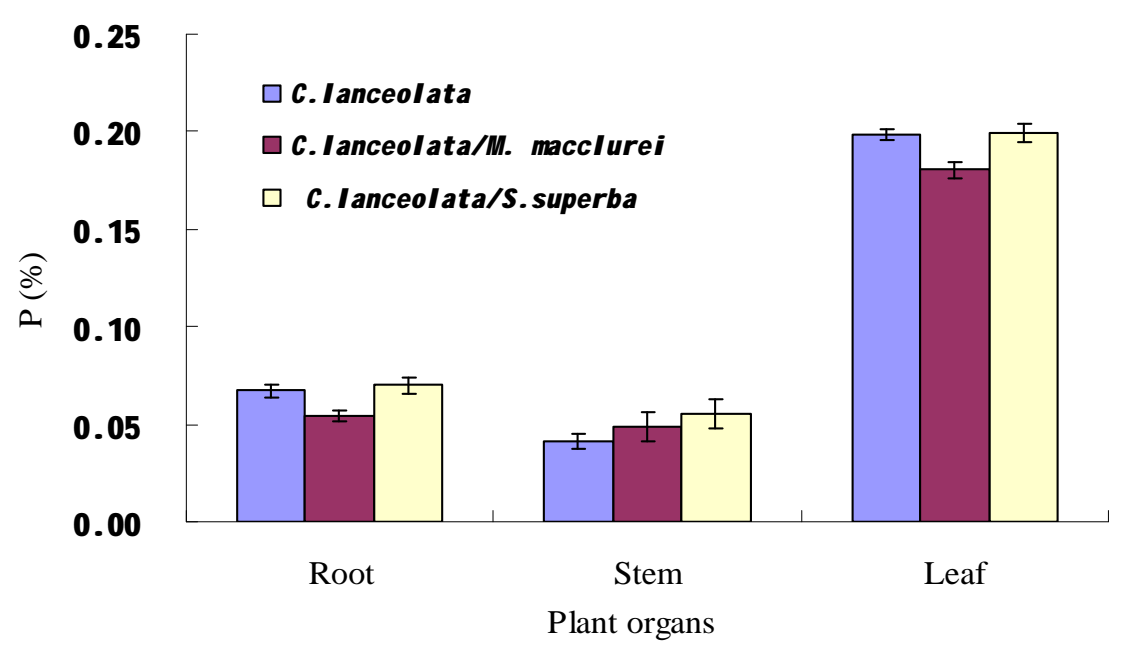

Fig. 4 Effect of mixed planting on $P$ content in $C$. lanceolata

\section{Conclusions}

Our results showed that mixed plantation of $C$. lanceolata with both $M$. macclurei and $S$. superba could increased $\mathrm{K}, \mathrm{Ca}, \mathrm{P}$ content to some extent, varying with different parts and plant variety used for the mixed planting with $C$. lanceolata. On the contrary, $\mathrm{Mg}$ content in mixed plantation of $C$. lanceolata generally was less than that in pure $C$. lanceolata. However, it should be mention that K, $\mathrm{Ca}$ and $\mathrm{P}$ are main macro nutrients for forest plant and it is more important in $\mathrm{P}$ deficient area. Therefore, mixed planting pattern could be a useful method to improve nutrient of $\mathrm{K}, \mathrm{Ca}$ and $\mathrm{P}$, and a mixed plantation of $C$. lanceolata with $S$. superba showed better than that $C$. lanceolata with $M$. macclurei.

\section{Acknowledgements}

This work was financially supported by the National Natural Science Foundation of China (31370609).

\section{References}

[1] Tang X, Pérez-Cruzado C, Vor T, et al. 2016. Development of stand density management diagrams for Chinese fir plantations. Forestry, 89: 36-45

[2] Wang Z, Chen J, Liu W, et al. 2013. Transcriptome characteristics and six alternative expressed genes positively correlated with the phase transition of annual cambial activities in Chinese fir (Cunninghamia lanceolata (Lamb.) Hook). PLoS ONE 8:e71562

[3] Bi J, Blanco JA, Seely B, et al. 2007. Yield decline in Chinese-fir plantations: a simulation investigation with implications for model complexity. Canadian Journal of Forest Research, 37:615-630 
[4] Wang Q, Wang S, Yu X. 2011. Decline of soil fertility during forest conversion of secondary forest to Chinese fir plantations in subtropical China. Land Degradation and Development, 22:444-452

[5] Ma XQ. 2001. Advance in researches on productivity decline of replanting Chinese-fir forests. Journal of Fujian College of Forestry, 21: 380-384

[6] Anna E, Richards AE, Forrester DI, et al. 2010. The influence of mixed tree plantations on the nutrition of individual species: a review. Tree Physiology, 30:1192-1208

[7] Zhang J, Wang S, Feng Z, et al. 2009. Carbon mineralization of soils from native evergreen broadleaf forest and three plantations in mid-subtropic China. Communications in Soil Science and Plant Analysis, 40: 1964-1982

[8] Wei X, Juan A. Blanco JA. 2014. Significant increase in ecosystem C can be achieved with sustainable forest management in subtropical plantation forests. PLoS ONE, 9: 1932-6203

[9] Wang Q, Wang S. 2008. Soil microbial properties and nutrients in pure and mixed Chinese fir plantations. Journal of Forestry Research, 19:131-135

[10] Ranade-malvi U. 2011. Interaction of micronutrients with major nutrients with special reference to potassium. Karnataka Journal of Agricultural Sciences, 24: 106-109

[11] Zou X,Wu P,Chen N. 2015. Chinese fir root response to spatial and temporal heterogeneity of phosphorus availability in the soil. Canadian Journal of Forest Research, 45: 402-410 